\title{
Dinâmicas de matrícula em escolas públicas na cidade do Rio de Janeiro $^{1}$
}

\section{School enrollment in public schools in Rio de Janeiro}

\author{
Rodrigo Rosistolato \\ Ana Pires do Pradoii \\ Mariane Campelo Koslinskiiii \\ Julia Tavares de Carvalhoiv \\ Amanda Morganna Moreirav
}

\begin{abstract}
iFaculdade de Educação, Universidade Federal do Rio de Janeiro, Rio de Janeiro, RJ, Brasil. rodrigo.rosistolato@gmail.com

iiFaculdade de Educação, Universidade Federal do Rio de Janeiro, Rio de Janeiro, RJ, Brasil. anapprado@yahoo.com

iiiFaculdade de Educação, Universidade Federal do Rio de Janeiro, Rio de Janeiro, RJ, Brasil. mckoslinski@gmail.com

ivFaculdade de Educação, Universidade Federal do Rio de Janeiro, Rio de Janeiro, RJ, Brasil. juliadecarvalho@gmail.com

vFaculdade de Educação, Universidade Federal do Rio de Janeiro, Rio de Janeiro, RJ, Brasil. morgannamoreira@hotmail.com
\end{abstract}

\footnotetext{
${ }^{1}$ Coordenação de Aperfeiçoamento de Pessoal de Nível Superior - CAPES; Fundação Carlos Chagas Filho de Amparo à Pesquisa do Estado do Rio de Janeiro - FAPERJ
} 


\section{pro.posições}

\section{Resumo}

Este estudo discute, com base na análise da alocação de alunos em um polo de matrícula, a distribuição de oportunidades educacionais e a existência de possíveis mecanismos de segregação escolar em escolas da rede municipal do Rio de Janeiro. O objetivo é compreender a distribuição dos alunos entre escolas na transição do $5^{\circ}$ para o $6^{\circ}$ ano do Ensino Fundamental, analisando as ações das famílias e da direção das escolas. O estudo combinou análises quantitativas e qualitativas. Utilizou-se a base de dados da Secretaria Municipal de Educação para análise dos padrões de envio de alunos. Realizaram-se entrevistas com 30 famílias e 3 diretores, para compreender os critérios das famílias para escolha de escolas, as estratégias para acessá-las e os procedimentos de matrícula adotados pelos gestores. Os resultados apontam a existência de padrões para envio de alunos a escolas com características semelhantes e mostram que as famílias seguem caminhos distintos para conseguir vagas nas escolas e que a direção das escolas tem papel ativo na seleção do alunado.

Palavras-chave: escolha escolar, burocracia educacional, segregação escolar, matrícula escolar

\section{Abstract}

This work discusses the distribution of educational opportunities and the existence of mechanism related to school segregation in the city of Rio de Janeiro educational system. In order to do so, it relies on student distribution analysis in a set of schools. The aim is to understand the distribution of pupils among schools in the transition from the fifth to sixth grade of elementary education by analyzing families and school administration's actions. The study bas combined quantitative and qualitative analysis. The analyses of the patterns of pupils exchange among schools were conducted using Local Educational Bureau datasets. We have conducted interviews with 30 families and three school principals to apprehend families' criteria to choose and strategies to access schools and the enrollment procedures adopted by school principals. The results suggest patterns of pupils exchange between schools that bear similar profiles. They show that families follow distinctive paths to reach the places at schools and that principals play an active role in pupils' selection.

Keywords: school choice, school segregation, school enrollment, educational opportunities 


\section{pro.p̣osıções}

\section{Introdução}

A cidade do Rio de Janeiro apresenta oferta universalizada no Ensino Fundamental, o que, a princípio, não incentivaria disputa por vagas em escolas. As regras de matrícula permitem que os familiares escolham quaisquer escolas para os filhos. Não há nenhum tipo de barreira legal de acesso, o que amplia as possibilidades de escolha. No entanto, embora exista oferta universal, os resultados das avaliações externas de aprendizagem apresentam discrepâncias de desempenho entre as escolas da rede, e as famílias que desejam matricular os filhos em escolas municipais enfrentam o desafio da escolha entre escolas com distintas características - inclusive aquelas localizadas no mesmo bairro -, no que se refere à qualidade, à eficácia, ao prestígio e ao alunado que recebem.

Considerando que as escolas não são iguais e que as famílias dispõem de mecanismos formais $^{2}$ de escolha de escolas, cabe indagar: Quais são os critérios estabelecidos pelas famílias para escolher as escolas municipais para seus filhos? Como conseguem a vaga na unidade desejada? Simultaneamente, em situações de maior demanda do que oferta, como as escolas definem os critérios de acesso e o público que frequentará determinada instituição? Como ocorre a distribuição de alunos nas escolas da rede?

Este artigo tem o objetivo de responder essas questões. $\mathrm{Na}$ primeira parte, apresentaremos a discussão - nacional e internacional - sobre escolha e acesso às escolas. $\mathrm{Na}$ sequência, descreveremos a metodologia utilizada no mapeamento e na análise dos dados. A terceira parte será destinada à apresentação dos dados quantitativos e qualitativos que sustentam os argumentos presentes no trabalho. Demonstraremos que a escolha escolar e o acesso às escolas, principalmente às de maior desempenho e melhor reputação, dependem de um conjunto de interações entre as famílias e a burocracia municipal. Tais interações são orientadas por relações anteriores estabelecidas entre as familias e a burocracia e/ou pelas visões que a burocracia educacional apresenta com relação às crianças matriculadas nas escolas públicas.

\footnotetext{
${ }^{2}$ No município do Rio de Janeiro, a regulamentação que orienta a distribuição de vagas escolares permite que os pais escolham, em tese, qualquer escola da rede (Bruel, 2014). Em outros estados e municípios brasileiros, o mesmo não acontece, pois o procedimento de distribuição de vagas ocorre segundo a localização do aluno em relação à jurisdição escolar. Para entender tais modelos de matrícula e seus contrastes na distribuição de oportunidades escolares, ver Costa, Alves, Moreira e Sá (2013).
} 


\section{pro.posıções}

Esses diálogos fazem com que as vagas nas escolas mais disputadas não sejam distribuídas de forma aleatória e, em decorrência disso, as crianças sejam divididas entre as escolas de maior e menor desempenho, sem considerar critérios republicanos. Esse processo, consequentemente, aumenta a segmentação entre as escolas e propicia que as crianças tenham acesso a diferentes níveis de conhecimento escolar durante o Ensino Fundamental.

\section{O debate sobre escolha escolar e acesso às escolas}

A distribuição desigual de alunos entre escolas é um tema amplamente discutido por estudos que abordam os processos de escolha dos estabelecimentos escolares pelas famílias. Tais estudos observam que há distintas capacidades de escolha e que diversos fatores influenciam esse processo (Alegre \& Bentino, 2012; Ball \& Vincent, 1998; Bell, 2005; Holme, 2002; Resende, Nogueira, Marques, \& Nogueira, 2011). Nesses trabalhos encontramos debates sobre as barreiras estruturais que levam a diferentes formas e resultados de escolha, como: os recursos disponíveis para cada família, a geografia objetiva de oportunidades educacionais e as limitações/possibilidades de escolha. Também ocorrem reflexões sobre famílias que, embora tenham os mesmos recursos, os combinam de formas diferenciadas ou traçam estratégias para cada filho. Sendo assim, há fatores que diferenciam as famílias no processo de escolha, como: as suas concepções sobre a qualidade das escolas e a valorização delas, seus diferentes projetos educacionais, as visões dos pais sobre a capacidade acadêmica de cada filho e as expectativas de escolarização. Além disso, as familias traçam diferentes estratégias ou combinações dos recursos disponíveis para alcançar a escola de preferência.

No entanto, os estudos que focalizam as escolhas dos estabelecimentos escolares raramente analisam os entraves do acesso às escolas impostos pelo agregado das ações das famílias e/ou pela ação das escolas ou dos agentes da burocracia escolar. Tampouco discutem as estratégias de acesso traçadas pelas famílias para lidar com esses entraves.

Nesse sentido, o estudo de Yair (1996) ressalta a importância de considerar não somente o perfil das famílias que fazem a escolha, mas o agregado de várias dessas famílias. $\mathrm{O}$ autor argumenta que esse cenário pode oferecer à escola concorrida o poder de decidir como lidar com o quadro de maior demanda do que oferta. Yair (1996) enfatiza a análise das 


\section{pro.posıções}

articulações entre as escolas, o que denomina "ecologia do mercado escolar"”. A ideia expressa a existência de um equilíbrio entre as escolas de um dado contexto, na medida em que aquelas de maior poder de seletividade dependem de outras que recebam os alunos que são delas expelidos. Podemos dizer, então, que há uma relação de interdependência entre as escolas: a partir do momento em que é possível uma escola decidir se vai ou não conceder a vaga para determinado aluno, imediatamente isso constrange a possibilidade de outro estabelecimento escolar também selecionar alunos.

Outros estudos analisam o desenho da legislação de matrícula e as limitações e as possibilidades que apresentam para a ação das famílias e das escolas e, consequentemente, para a distribuição do alunado entre escolas. Por exemplo, estudos realizados em países europeus, nos Estados Unidos e no Chile, observaram o impacto de regras de matrícula sobre a segregação escolar (Elacqua, 2012; Glenn, 2009; Gorard, Taylor, \& Fitz, 2003; Noreisch, 2007).

Estudos referentes ao sistema educacional inglês e alemão analisam o papel da burocracia educacional no processo de matrícula dos alunos. Na Inglaterra, há uma série de regras que restringem as possibilidades de escolha por parte das escolas, como os critérios para admitir alunos e os procedimentos, em caso de maior demanda do que oferta, que podem envolver tomadas de decisões de instâncias superiores às escolas, tornando o processo ainda mais objetivo e democrático (West, Hind, \& Pennell, 2004).

Em Berlim, as diferentes interpretações feitas pelos pais indicam que o sistema de matrícula é intencionalmente mantido não transparente e difuso, justamente para assegurar a flexibilidade na admissão dos alunos nas escolas (Noreisch, 2007). Nesse cenário, os diretores geralmente possuem o voto conclusivo sobre os pedidos dos pais, ou seja, são os gatekeepers ${ }^{4}$ das vagas escolares mais procuradas. Com esse estudo, Noreisch (2007) mostrou que as diferentes brechas nas regras de matrícula são aproveitadas tanto por pais de alunos bem informados sobre tais regras quanto pela burocracia educacional. Esse conjunto de estudos nos permitiu construir hipóteses sobre os processos de escolha e acesso às escolas no Rio de Janeiro.

\footnotetext{
${ }^{3}$ É importante ressaltar que essa ecologia ou equilíbrio é produto do agregado das ações dos indivíduos. O autor trabalha com a ideia de estrutura como um agregado de ações individuais que é produto dessas ações.

4 Uma possível tradução para o conceito de gatekeepers utilizado por Noreisch (2007) seria "guardiões do portão".
} 


\section{pro.posições}

Além da literatura internacional sobre escolha escolar e dos estudos sobre as relações família-escola no Brasil (Nogueira, 2005), pesquisas anteriores já indicavam que as escolas da rede municipal do Rio de Janeiro possuíam reputações diferentes na perspectiva de familiares e estudantes. Costa (2008) apontou a correlação entre a reputação das escolas e o perfil sociocultural do alunado, aliado a uma relativa homogeneidade do alunado. Estudos posteriores identificaram padrões desiguais de distribuição no momento de remanejamento em bloco de alunos entre as escolas da rede. A partir da estimação de modelos de regressão logística, observaram que as chances de acesso às escolas de anos finais que apresentam maior performance em avaliações externas estavam condicionadas ao prestígio da escola de origem, à escolaridade dos pais, à trajetória escolar e à defasagem idade-série (Bruel \& Bartholo, 2012; Costa \& Koslinski, 2011; Koslinki, Costa, Bruel, \& Bartholo, 2014), à cor (Costa, Alves, Moreira, \& Sá, 2013) e à estrutura familiar dos alunos (Bruel \& Bartholo, 2012). A partir desses resultados, os estudos propuseram a hipótese de que, ao menos em parte, a hierarquização entre as escolas era resultante de processos relacionados à oferta escolar. No entanto, apesar da realização de análises em grande escala, utilizando um grande número de escolas e de alunos, os processos de escolha e a suposta seleção de alunos pelas escolas não tinham sido investigados (Bruel \& Bartholo, 2012). Em estudos posteriores sobre as estratégias das famílias, há trabalhos que indicam alguns tipos de escolha e de acesso às escolas em que as famílias levavam em conta e/ou eram influenciadas pela ação de atores da burocracia escolar (Rosistolato \& Pires do Prado, 2012, 2013; Rosistolato, Pires do Prado, Moreira, \& Fernandes, 2015; Rosistolato, 2015). Citamos como exemplo o que os autores classificam como "escolha dirigida", em que familiares acatam as indicações realizadas pela burocracia municipal para o preenchimento da lista de escolas de preferência. Além dela, os autores apresentam como estratégia de acesso o recurso a "relações pessoais na burocracia municipal", que caracteriza os processos de matrícula em que os pais utilizam redes de solidariedade e de relações pessoais com pessoas da própria burocracia municipal ou com pessoas que os conectam a ela para o início do processo de matrícula na escola desejada. Rosistolato et al. (2015) também observaram um papel ativo, desempenhado tanto por instâncias intermediárias da Secretaria Municipal de Educação como por diretores das escolas nos processos e na distribuição de matrículas.

Neste trabalho, pretendemos contribuir para a discussão sobre a distribuição dos alunos na rede municipal do Rio de Janeiro, analisando, simultaneamente, (1) os 


\section{pro.posições}

procedimentos de escolha e acesso realizados pelas famílias para conseguir uma vaga na escola de preferência - diante das barreiras impostas por atores da burocracia educacional - e (2) as tomadas de decisão dos diretores das escolas no processo de matrícula. Em síntese, estamos trabalhando com as dinâmicas relacionadas à oferta e à demanda por vagas em escolas municipais. Analisaremos esses processos com base no estudo de um polo de matrícula localizado na zona norte do Rio de Janeiro.

Um polo de matrícula é caracterizado por um conjunto de escolas localizadas próximas geograficamente, constituindo uma organização para fins de alocação de alunos em períodos de matrícula no final de um ano letivo. Até 2009, uma das escolas de cada polo cedia seu espaço físico para os processos de matrícula de todas as outras pertencentes ao seu grupo. No entanto, em 2010, o procedimento modificou-se ${ }^{5}$ : para os alunos que não fazem parte da rede, a família deve solicitar a vaga online ${ }^{6}$. Para os alunos que já fazem parte da rede, há dois processos possíveis: transferência interna e remanejamento.

A transferência interna ocorre durante todo o ano letivo para alunos que desejam fazer transferências para escolas da rede municipal. O procedimento pode ser realizado online no período determinado pela Secretaria Municipal de Educação ou diretamente, nas escolas desejadas, após o período específico de matrícula ${ }^{7}$.

O remanejamento ocorre quando a escola não oferece o segmento seguinte àquele que o aluno está por concluir. A rede pública municipal do Rio de Janeiro possui diversas escolas que atendem apenas ao $1^{\circ}$ segmento (do $1^{\circ}$ ao $5^{\circ}$ ano), e é necessário que as famílias busquem escolas que ofereçam o $2^{\circ}$ segmento (do $6^{\circ}$ ao $9^{\circ}$ ano $)^{8}$. Nesses casos, as escolas de $1^{\circ}$ segmento remanejam os alunos em bloco para outra escola que ofereça o próximo segmento dentro do mesmo polo de matrícula. Nesse momento, as escolas de $1^{\circ}$ segmento estabelecem certo "convênio" com as escolas de $2^{\circ}$ segmento". Caso o responsável, por algum motivo, não

\footnotetext{
${ }^{5}$ Para a explicação das etapas do processo de matrícula, ver estudo de Bruel (2014).

6 Disponível em: http://www.rio.rj.gov.br/dlstatic/10112/4463799/4112236/GUIA_matriculageral_ 201414.11.pdf

7 Para um debate sobre as transferências internas, ver Rosistolato et al. (2015).

8 A rede municipal tem escolas que oferecem somente o $1^{\circ}$ segmento do Ensino Fundamental (do $1^{\circ}$ ao $5^{\circ}$ ano), outras que disponibilizam apenas o $2^{\circ}$ segmento (do $6^{\circ}$ ao $9^{\circ}$ ano) e outras, ainda, que dispõem dos dois segmentos (do $1^{\circ}$ ao $9^{\circ}$ ano).

${ }^{9}$ Como indica o estudo de Koslinski \& Carvalho (2015), o fluxo entre as escolas que só oferecem o $1^{\circ}$ segmento e as escolas que oferecem $2^{\circ}$ segmento não parece ser aleatório e sugere um aparente convênio entre as escolas. As autoras demonstram que esse convênio ocorre entre escolas de $1^{\circ}$ e $2^{\circ}$ segmentos que apresentam perfis semelhantes.
} 


\section{pro.posıções}

queira seguir o remanejamento, ele pode escolher a escola do seu filho através da matrícula online ou pode buscar vagas direto na escola que deseja, fora do prazo de matrícula online.

O trabalho de Bruel (2014) analisa detalhadamente a política de matrícula do município do Rio de Janeiro. Especificamente sobre o remanejamento, o estudo indica que cada Coordenadoria Regional de Educação (CRE) possui autonomia para definir se as escolas devem pedir às famílias que indiquem os estabelecimentos de ensino de preferência ou se as próprias instituições (escolas e CRE) definirão as escolas de destino dos estudantes. A autora salienta que ambas as situações estão amparadas pelas normas formais de matrícula, entretanto, produzem efeitos distintos: enquanto em uma das situações os pais têm maior poder de decisão sobre a vida escolar dos filhos, na outra, a burocracia educacional é que decide a sequência da escolarização dos alunos.

Considerando a direção escolar como um dos principais agentes responsáveis pelo momento de remanejamento, o trabalho partiu da hipótese, de um lado, de que as famílias escolhem as escolas utilizando suas redes de solidariedade e sua experiência nas instituições escolares; e conseguem a vaga, frequentemente, a partir de regras informais. De outro lado, a burocracia teria um papel ativo no processo de distribuição de vagas: os alunos seriam remanejados do $1^{\circ}$ para o $2^{\circ}$ segmento, em escolas do mesmo polo, de acordo com regras não formais definidas pelos diretores.

\section{Metodologia}

O estudo utilizou uma base de dados disponibilizada pela Secretaria Municipal de Educação do Rio de Janeiro ${ }^{10}$, com informações sobre o alunado da rede. Os principais dados utilizados foram: (a) escolarização dos pais; (b) escolas frequentadas no $5^{\circ}$ ano em 2009 e no $6^{\circ}$ ano em 2010. Com isso, foi possível analisar o perfil das escolas e o fluxo de alunos entre o $1^{\circ}$ e o $2^{\circ}$ segmentos. Optamos por realizar as análises em duas Coordenadorias Regionais de Educação - a segunda e a quarta CRE. Elas foram escolhidas porque são estratificadas em nível socioeconômico e desempenho escolar, considerando a diversidade e a localidade do público que atendem. Nessas CRE, escolhemos dois polos de matrícula. A escolha levou em

\footnotetext{
${ }^{10}$ É importante salientar a disponibilidade da Secretaria Municipal de Educação do Rio de Janeiro em ceder os dados. Sem eles, este estudo seria inviabilizado.
} 


\section{pro.posıções}

consideração a presença de escolas de baixo e alto desempenho, a movimentação de alunos em bloco (remanejados), o desvio-padrão da média de escolaridade dos pais e a concentração de escolas próximas umas das outras.

Neste artigo, estamos trabalhando, exclusivamente, com os dados referentes ao polo da quarta Coordenadoria Regional de Educação, em que percebemos padrões não aleatórios de remanejamento de alunos entre as escolas. Há uma tendência das escolas de $1^{\circ}$ segmento com maior nível socioeconômico e maiores notas padronizadas na Prova Brasil para remanejar alunos para escolas de $2^{\circ}$ segmento com o mesmo perfil. Para entender esse processo, realizamos entrevistas com famílias e com diretores de escolas. Selecionamos membros da direção de escolas do polo analisado que apresentavam características "extremas" de desempenho e perfil do alunado ${ }^{11}$. Entrevistamos ${ }^{12}$ a direção da Escola I, da Escola A e da Escola $G$, para entender os procedimentos de matrícula adotados pelos atores que compõem a burocracia educacional.

Para compreender o ponto de vista das famílias que participaram dos processos de matrícula, selecionamos famílias cujos filhos trocaram de escola ao concluírem o $5^{\circ}$ ano do Ensino Fundamental. O cadastro geral dos alunos nos permitiu realizar uma amostra aleatória. Podemos dizer que essa é uma inovação trazida por este trabalho, porque os estudos sobre estratégias familiares de escolarização tendem a utilizar amostras por conveniência, por conta da ausência de qualquer marco amostral. No polo analisado, tínhamos um universo de 310 alunos que realizaram essa troca de escola. Selecionamos 30 deles para aplicação de questionários, entrevistas e observações etnográficas com suas famílias.

$\mathrm{Na}$ sequência, apresentaremos os dados quantitativos sobre o polo estudado e o fluxo de alunos entre as escolas. Em seguida, analisaremos os dados qualitativos relativos às ações das famílias e dos diretores no momento de matrícula escolar. Essa estratégia metodológica permitiu que entendêssemos, simultaneamente, os processos de escolha e acesso às escolas com base na análise das interações entre gestores e famílias no momento da matrícula escolar.

\footnotetext{
11 As características das escolas estão na Tabela 2, inserida na próxima seção. Na Tabela 1 é possível observar que os resultados da Escola I e da Escola A são superiores aos da Escola G, e elas estão nos extremos da classificação por desempenho e perfil do alunado das escolas do polo estudado.

12 Também contatamos a Escola J para realização de entrevistas, mas a equipe não pôde concedê-la.
} 


\section{pro.posições}

\section{Análise de dados}

As escolas pertencentes ao polo escolhido para este estudo possuem distintos perfis de alunos e discrepâncias de desempenho nas avaliações externas de aprendizagem. A Tabela 1 apresenta dados das escolas que compõem o universo estudado, informando a proporção de alunos cujos pais possuem alta escolaridade ${ }^{13}$ e as médias das notas padronizadas da Prova Brasil dos últimos anos ${ }^{14}$.

\begin{tabular}{|c|c|c|c|c|c|}
\hline \multicolumn{3}{|c|}{ ESCOLASDE $1^{\circ}$ SEGMENTO } & \multicolumn{3}{|c|}{ ESCOLAS DE $2^{\circ}$ SEGMENTO } \\
\hline Escolas & $\begin{array}{l}\% \text { de alunos com } \\
\text { alta escolaridade } \\
\text { dos pais (2009) }\end{array}$ & $\begin{array}{l}\text { Prova Brasil } \\
\text { Padronizada } \\
(2005,2007, \\
2009,2011)\end{array}$ & Escolas & $\begin{array}{l}\% \text { de alunos com } \\
\text { alta escolaridade } \\
\text { dos pais (2009) }\end{array}$ & $\begin{array}{l}\text { Prova Brasil } \\
\text { Padronizada } \\
(2005,2007, \\
2009,2011)\end{array}$ \\
\hline A & 62,26 & 6,28 & I & 62,86 & 6,09 \\
\hline B & 47,78 & 6,11 & II & 34,06 & 4,73 \\
\hline $\mathrm{C}$ & 51,10 & 5,92 & & & \\
\hline $\mathrm{D}$ & 28.22 & 5,39 & & & \\
\hline $\mathbf{E}$ & 27,85 & 5,30 & $\mathbf{E}$ & 29,22 & 4,39 \\
\hline $\mathbf{F}$ & 42,51 & 5,20 & & & \\
\hline G & 31,98 & 5,20 & G & 29,97 & 4,61 \\
\hline $\mathrm{H}$ & 21,85 & 5,18 & $\mathrm{H}$ & 15,41 & 4,48 \\
\hline $\mathbf{J}$ & 13,86 & 4,71 & & & \\
\hline Média & 36,37 & 5,47 & Média & 34,30 & 4,86 \\
\hline $\begin{array}{l}\text { Desrio- } \\
\text { Padrăo }\end{array}$ & 15,53 & 0,51 & $\begin{array}{l}\text { Desrio- } \\
\text { Padrăo }\end{array}$ & 17,44 & 0,69 \\
\hline
\end{tabular}

Fonte: Prova Brasil 2005-2011 (INEP/MEC) e dados administrativos da SME Rio de Janeiro (Retirado de http://portal.inep.gov.br/web/portal-ideb/planilhas-para-download)

Observamos que a média da nota da Prova Brasil Padronizada (PBP) diminui progressivamente nas escolas de $1^{\circ}$ segmento e também nas de $2^{\circ}$ segmento. Enquanto essa diminuição parece estar correlacionada à proporção de alunos de $2^{\circ}$ segmento que têm pais com alta escolaridade, a mesma associação não pode ser feita para as escolas de $1^{\circ}$ segmento. Algumas dessas escolas apresentam maior desempenho medido pela Prova Brasil, se comparadas a outras com maiores proporções de alunos com pais mais escolarizados, como é o caso das Escolas E, F e G. Isso era esperado, considerando que a escolaridade dos pais não

\footnotetext{
13 Essa variável foi calculada com base em uma variável ordinal que indica a escolarização dos pais dos alunos. Ela está disposta no banco de dados da seguinte maneira: 0 para pais analfabetos; 1 para pais com Ensino Fundamental incompleto; 2 para pais com Ensino Fundamental completo; 3 para pais com Ensino Médio; 4 para pais com Ensino Superior. Foram considerados pais com alta escolaridade aqueles que completaram o Ensino Médio e o Ensino Superior.

14 A nota da Prova Brasil Padronizada foi calculada com base na média das notas da Prova Brasil de 2005, 2007, 2009 e 2011.
} 


\section{pro.posições}

ISSN 1980-6248

é o único fator associado ao desempenho dos alunos, e as relações entre tais variáveis são probabilísticas.

Comparando as escolas de $2^{\circ}$ segmento, é possível verificar uma polarização entre a Escola I, com 62,86\% de alunos com pais de alta escolaridade, e as demais escolas do polo, com valores que variam de $34,06 \%$ a 15,41\%. O mesmo padrão é observado em relação à nota na Prova Brasil: a Escola I apresentou uma nota média em torno de 2 desvios-padrão ou mais acima das demais escolas.

Para ilustrar a movimentação de alunos do $5^{\circ}$ para o $6^{\circ}$ ano do polo estudado, elaboramos um fluxograma com dados da Secretaria Municipal de Educação de 2009 e $2010^{15}$. O fluxograma dispõe as escolas em ordem decrescente de desempenho medido pela Prova Brasil Padronizada. A primeira coluna agrupa as escolas do $1^{\circ}$ segmento, e a segunda coluna, escolas de $2^{\circ}$ segmento. Optamos por apresentar, no fluxograma, apenas a movimentação dos alunos oriundos das escolas $\mathrm{C}$ e $\mathrm{E}$, pois as entrevistas que realizamos com os responsáveis dizem respeito apenas a elas ${ }^{16}$. As setas apresentam diferentes larguras e tipos de traço e indicam se a frequência de alunos remanejados entre as escolas foi abaixo, acima ou equivalente à frequência esperada ${ }^{17}$.

Ao observarmos o fluxograma, o primeiro ponto que chama atenção são os envios, maiores do que o esperado, de ambas as escolas de $1^{\circ}$ segmento. A escola $\mathrm{C}$, que apresenta a terceira maior média na PBP e 51,10\% de alunos cujos pais possuem alta escolaridade, envia um quantitativo de alunos superior ao previsto para escolas com características bastante distintas, que são as escolas I e G. Enquanto a escola I possui o maior PBP, considerando os estabelecimentos de $2^{\circ}$ segmento desse polo, e 62,01\% de alunos com pais mais escolarizados,

15 O fluxograma ilustra um padrão de movimentação de alunos entre escolas do polo estudado, que tende a ser estável. Optamos por apresentar os dados de 2009 e 2010, pois são as bases de que dispomos, que apresentavam dados mais confiáveis para tais anos. As bases de anos mais recentes apresentavam maior quantidade de dados faltantes, que podem ser decorrentes da ausência de informação ou de informação errada.

16 Carvalho (2014) observou o fluxo de alunos em todas as escolas desse polo e Koslinski e Carvalho (2015) analisaram mais detalhadamente a movimentação dos alunos do $5^{\circ}$ para o $6^{\circ}$ ano em todas as escolas de duas Coordenadorias Regionais de Educação (CRE), incluindo a que pertence o polo foco do presente artigo.

17 O fluxograma foi elaborado a partir de uma tabela de contingência com as frequências de alunos remanejados e/ou transferidos entre as escolas do polo que compõem o foco deste artigo. A partir das frequências, foram calculadas as estatísticas do quiquadrado para a tabela e os resíduos ajustados padronizados para cada célula. As células com frequências de alunos transferidos/remanejados entre as escolas que ultrapassaram consideravelmente a frequência esperada (resíduos padronizados ajustados, iguais ou superiores a +2 ) foram representadas no fluxograma pelas setas sólidas com maior espessura. Por sua vez, as células com frequências de movimentação de alunos entre escolas que estavam consideravelmente abaixo do esperado (resíduos padronizados ajustados iguais ou inferiores a -2) foram representadas por setas pontilhadas. As demais frequências foram consideradas como "normais", ou seja, próximas às frequências esperadas. 


\section{pro.posıções}

a escola $G$ apresenta o segundo menor PBP e menos de um terço de alunos com pais mais escolarizados. Quanto aos demais envios de alunos da escola C, apenas para a escola II o envio está próximo à frequência esperada. Para as outras escolas, ficou abaixo.

$\mathrm{Na}$ escola E, podemos observar a "inércia" de seus alunos ao final do $5^{\circ}$ ano, ou seja, o fluxo para outras escolas é menor que a frequência esperada. Essa escola oferece os dois segmentos do Ensino Fundamental (do $1^{\circ}$ ao $9^{\circ}$ ano) e é razoável pensar que grande parte de seus alunos permaneça na escola na transição de segmentos. Embora ela aumente sua oferta de vagas a partir do $6^{\circ}$ ano e, portanto, também receba alunos remanejados das escolas que só têm o $1^{\circ}$ segmento do Ensino Fundamental, essa movimentação é abaixo da frequência esperada em relação aos alunos oriundos da escola C.

Figura 1. Fluxograma da movimentação dos alunos do $5^{\circ}$ para o $6^{\circ}$ ano

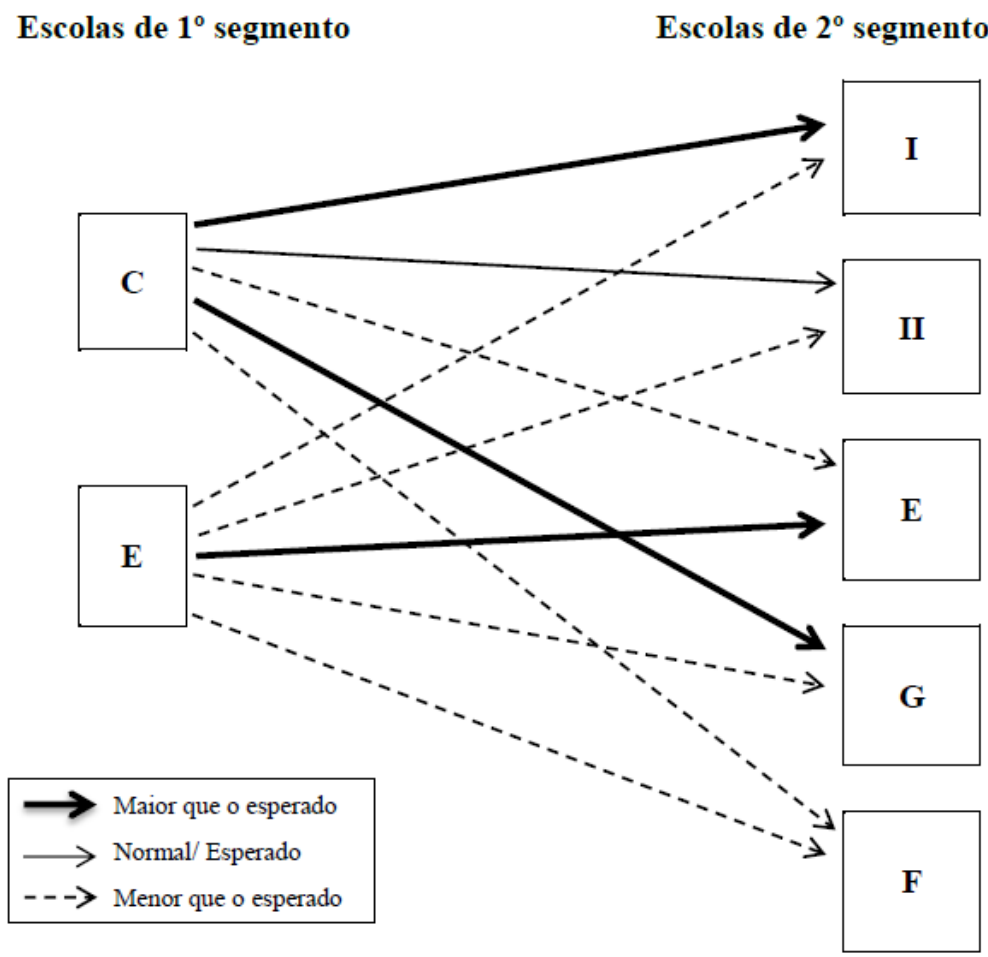

Fonte: Elaboração própria, utilizando dados administrativos da Secretaria Municipal de Educação do Rio de Janeiro. 


\section{pro.posições}

\section{O ponto de vista das famílias sobre escolha e acesso às escolas}

Dentre as 30 famílias da amostra, 17 apresentaram critérios de escolha e estratégias de acesso às escolas em que desejavam matricular seus filhos. Na Tabela 2 mostramos as escolas em que os filhos dessas famílias estavam matriculados, as escolhas feitas pelos responsáveis no momento do remanejamento e as escolas em que conseguiram as vagas.

Tabela 2 - Escolha e acesso às escolas desejadas pelas famílias

\begin{tabular}{cccc}
\hline Aluno & $\begin{array}{c}\text { Escola de } \\
\text { origem }\end{array}$ & $\begin{array}{c}\text { Escola } \\
\text { desejada }\end{array}$ & $\begin{array}{c}\text { Escola } \\
\text { matriculada }\end{array}$ \\
\hline Aline & Escola E & Escola I & Escola I \\
Carlos & Escola C & Escola I & Escola I \\
Cleiton & Escola D & Escola I & Escola I \\
Evandro & Escola D & Escola I & Escola I \\
Fabiana & Escola II & Escola I & Escola I \\
José & Escola C & Escola I & Escola II \\
Mirian & Escola D & Escola I & Escola I \\
Thais & Escola B & Escola I & Escola I \\
Vanessa & Escola C & Escola I & Escola II \\
Vivian & Escola D & Escola I & Escola I \\
Anderson & Escola D & Escola II & Escola II \\
Fernanda & Escola D & Escola II & Escola II \\
Jair & Escola J & Escola II & Escola II \\
Marcos & Escola C & Escola II & Escola II \\
Pietro & Escola D & Escola E & Escola E \\
Sabrina & Escola B & Escola E & Escola E \\
Lucas & Escola H & Escola G & Escola G \\
\hline
\end{tabular}

Fonte: Elaboração própria, utilizando dados da pesquisa realizada com as famílias

O primeiro resultado que encontramos é a correspondência entre a escolha das famílias e a escola com maior desempenho na Prova Brasil ${ }^{18}$. As famílias organizam as escolas em hierarquias de prestígio e compartilham em suas redes de sociabilidade as visões que têm sobre as escolas do bairro. A Escola I foi a que recebeu um maior número de avaliações positivas. Ela é a que tem maior desempenho e maior porcentagem de pais com alta escolaridade; além disso, é a que se distancia geograficamente das demais escolas do polo.

Observamos que as famílias não apenas reconhecem como melhor escola aquela que tem maior desempenho na Prova Brasil e com perfil de alunado com pais mais escolarizados, mas também desejam matricular seus filhos na Escola I. Dentre os 17 pais que optaram, 10

\footnotetext{
18 Os nossos resultados seguem a constatação feita por Costa (2008), que demonstrou que as classificações dos pais tendem a coincidir com o desempenho das escolas.
} 


\section{pro.posıções}

pretendiam essa escola para seus filhos. No entanto, a escolha não necessariamente possibilitou a obtenção da vaga almejada: dessas 10 famílias, 8 conseguiram matricular seus filhos na Escola I. As famílias indicam que existem critérios de seleção para matrícula na Escola I, o que os leva a percorrer caminhos diferentes para o acesso às escolas ${ }^{19}$.

Selecionamos seis casos exemplares que nos permitem refletir sobre os processos utilizados pelas famílias no momento de escolha e acesso às escolas municipais. Primeiro apresentaremos quatro casos que descrevem as trajetórias de alunos que estudaram na Escola $\mathrm{C}$ durante o $5^{\circ}$ ano e suas famílias escolheram matriculá-los na Escola I no $6^{\circ}$ ano. Contudo, relataram processos diferentes no momento do remanejamento e para a obtenção da vaga desejada. Em seguida, exporemos dois casos em que, embora tenha havido interferência das relações pessoais internas à burocracia municipal nos processos de escolha, não foi obtida a vaga na escola desejada. Em ambos os casos, foi feita uma transferência interna entre escolas da rede.

O primeiro dos seis casos é o do aluno José ${ }^{20}$. Sua mãe cursou até o quarto ano do Ensino Fundamental e está desempregada. Ela o considera um bom aluno e espera que o filho conclua o Ensino Médio. José estudava na Escola C. No período do remanejamento, a direção entregou para ela um documento em que deveria citar as três escolas de sua preferência. A mãe escolheu, nesta ordem, a Escola I, a Escola G e a Escola II. Ela queria que o filho estudasse na Escola I, porque "falam que é uma das melhores escolas do bairro".

O aluno foi encaminhado para a última opção listada pela mãe, a Escola II. Na tentativa de entender o processo, a mãe procurou a diretora da escola de $1^{\circ}$ segmento, buscando o motivo de não ter sua escolha respeitada. Segundo a responsável, a diretora respondeu que "não tinha vaga" e a prioridade era "para alunos que já tinham irmãos matriculados na escola”. Diante disso, a mãe de José acatou a indicação da escola, matriculando o filho na Escola II.

O segundo caso diz respeito ao aluno Carlos. Sua mãe trabalha como auxiliar de limpeza e possui o Ensino Médio completo. Para a mãe, Carlos é um bom aluno, o que faz com que ela tenha expectativas de escolarização de longo prazo. Ela espera que o filho chegue até a faculdade. Quando Carlos precisou trocar de escola no período do remanejamento, a

19 Estudos realizados por Costa, Pires do Prado e Rosistolato (2012) analisaram as estratégias familiares e indicaram tipologias de escolha e acesso.

20 Todos os nomes são fictícios. 


\section{pro.posıções}

mãe estava determinada a matriculá-lo na Escola I, para ela, a melhor do bairro. Seus filhos mais velhos já haviam estudado lá. Por isso, desde que Carlos iniciou sua trajetória escolar, pensava em transferi-lo para a Escola I.

A mãe relatou que não foi difícil conseguir a vaga na Escola I. Segundo ela, a direção da Escola C, de $1^{\circ}$ segmento, fez uma reunião com os pais, para informá-los de que havia na Escola I dez vagas disponíveis, divididas igualmente para alunos cujos irmãos estudavam na Escola I e para os "melhores alunos". A mãe informou que, quando o número de concorrentes excede o número de vagas oferecidas pela Escola $\mathrm{I}$, a direção da escola de $1^{\circ}$ segmento seleciona os que podem concorrer às vagas. Como o irmão de Carlos estudava na Escola I, a mãe, nessa mesma reunião, manifestou seu desejo de matricular seu filho nessa escola e conseguiu a vaga. A mãe acredita que, se não tivesse filhos mais velhos estudando na Escola I, não teria conseguido matricular Carlos, pois "por ela ser a melhor escola, todo mundo quer ir pra lá. Por causa disso, é difícil mesmo".

O terceiro caso é o da aluna Bianca. Sua mãe tem 45 anos de idade, é formada em Pedagogia e trabalha como professora em uma escola particular. Ela nos contou que sua filha foi considerada uma das dez melhores alunas da Escola $C$ e, por esse motivo, foi selecionada para a Escola I:

a Escola C prepara e a gente já sabia que os melhores alunos iriam para a Escola I. Ai, desde que elas entraram aqui [na Escola C], elas estavam preparadas, condicionadas a essa vaga! ... Essa escola [Escola I] pega os melhores alunos pro $6^{\circ}$ ano.

A mãe de Bianca relatou que, antes do período de remanejamento, a direção da Escola $\mathrm{C}$ lhe explicou que sua filha seria transferida automaticamente para a Escola I devido às suas boas notas e ao seu desempenho escolar. Neste caso, a interferência da direção possibilitou a matrícula da aluna na escola com maior desempenho na Prova Brasil.

O quarto caso é o da aluna Vanessa. Sua mãe possui o Ensino Médio completo e trabalha como autônoma, fazendo "bicos". A mãe tem "fé em Deus" que sua filha cursará o Ensino Superior. Para ela, a menina é uma boa aluna. Vanessa também estudava na Escola C. A mãe contou que começou a pensar na troca de escola da filha no início do ano letivo. $\mathrm{O}$ processo de escolha começou quando a Escola C entregou um documento para os pais preencherem com opções de escolas, em ordem de preferência. A mãe listou, nesta ordem, a Escola I, a Escola II e a Escola G. Sobre o motivo de ter escolhido a Escola I como primeira 


\section{pro.posições}

opção, declarou: "todo mundo fala que a Escola I é uma escola boa, ... que as notas lá são muito bem aplicadas porque os professores puxam bastante. Ai en queria, né, experimentar, testar para ver se ela era realmente tudo isso".

No entanto, ela não conseguiu a vaga desejada. Vanessa foi encaminhada para a Escola II. A entrevistada declarou ser "bastante" difícil acessar a Escola I, porque todos acreditam que ela é a melhor escola do bairro. A mãe resolveu, então, "deixar para lá" e não procurou saber o motivo de não ter conseguido a vaga na escola desejada.

É interessante notar que as famílias parecem ser conscientes da existência de processos de seleção para obter a vaga em determinadas escolas, principalmente aquelas com maior prestígio, como é o caso da Escola I. Essa percepção contribui para que as famílias legitimem as decisões da direção na escolha escolar ${ }^{21}$ ou elaborem estratégias para conseguir a vaga na escola desejada - como veremos na descrição dos casos seguintes.

O quinto caso envolve a aluna Luiza. Sua mãe possui Ensino Superior completo e trabalha como supervisora de recursos humanos. Acredita que a filha cursará o Ensino Superior, pois tem incentivo da família e é uma aluna muito boa e disciplinada. Diferentemente dos casos descritos anteriormente, Luiza estudava em uma escola que oferecia os dois segmentos do Ensino Fundamental, a Escola E. No caso dela, não era necessário fazer o remanejamento para outra escola da rede. No entanto, a direção da Escola E aconselhou a família de Luiza a procurar vaga na Escola I, argumentando ser uma escola melhor para o perfil da aluna. A mãe de Luiza acatou a sugestão e procurou a direção da Escola I, mas a vaga foi negada, levando a responsável a procurar outra escola para matricular sua filha. Ela nos relatou os caminhos percorridos:

A coordenadora da Escola E disse que era melhor en colocar a Luiza na Escola I. Então en tirei ela de lá e fui matricular na Escola I. Quando en cheguei lá, adivinha? Não tinha mais vaga nenhuma! Pior que a coordenadora [da Escola E] tinha falado tão mal da Escola E ... ela disse que era fraco para minha filha, que ela tinha que ir para uma escola melhor. Ai, eu não quis colocar ela lá [na Escola E] de novo, não! ... escolbi a Escola G porque é mais perto ... ela vai a pé.

\footnotetext{
${ }^{21}$ Uma das famílias entrevistadas contou que, em reunião na escola de origem, a direção explicou que era justo que apenas os melhores alunos concorressem às vagas na Escola I. Nas palavras da mãe: "ela [a filha] não passou com nota boa, ai a professora falou que não achava justo mandar uma criança com $\mathrm{R}$ [regular] pra lá, junto com aquela criança que estudou o ano todo e passou com B [bom]". A mãe concluiu sua fala, dizendo que concordava com o argumento da professora e, por isso, desistiu de tentar vaga na Escola I.
} 


\section{pro.posições}

Não tendo conseguido a vaga na escola indicada pela direção, a mãe de Luiza dirigiu-se a outra escola do polo, a Escola G. Segundo a mãe, ao explicar o ocorrido à coordenadora da Escola $G$, obteve a vaga.

O sexto caso diz respeito à aluna Aline, que também estudava na Escola E. Assim como Luiza, Aline estava em uma escola que oferecia os dois segmentos do Ensino Fundamental, e não era necessário fazer o remanejamento. No entanto, sua mãe, que é faxineira e tem o Ensino Fundamental completo, queria transferir a filha para a Escola I. Segundo ela, a Escola I tem boa fama na vizinhança, e a tia de Aline trabalhava como merendeira na escola e a descrevia positivamente. Desse modo, a mãe pediu para que a tia tentasse uma vaga para que Aline fosse transferida para a Escola I. A tia procurou a diretora da Escola I e conseguiu a vaga para a sobrinha. Aline é considerada uma aluna regular, e sua mãe acredita que ela completará apenas o Ensino Médio, devido a sua falta de interesse nos estudos. Isso preocupa a mãe, pois acha que ela pode perder a vaga. A tia, no entanto, a tranquiliza, dizendo que a sobrinha não ganhou uma bolsa de estudos, mas uma "ajudinha".

Os quatro primeiros casos descritos demonstram que na mesma escola há distintos procedimentos de remanejamento. A direção permite a escolha das escolas pelas famílias, mas a obtenção da vaga é definida pela burocracia, dependendo do perfil das famílias e do aluno. As famílias que já possuem filhos na Escola I - como é o caso de Carlos - têm a possibilidade de acessar a escola de $2^{\circ}$ segmento do bairro com maior desempenho na Prova Brasil. Os pais indicam que os alunos com melhor desempenho também têm a garantia de acesso na Escola I, como descrito no caso da aluna Bianca. Sendo assim, os dados apontam que a direção da escola de $1^{\circ}$ segmento mescla regras formais e informais de acesso à escola de $2^{\circ}$ segmento: permite, tal como indica a legislação, a escolha e o acesso de irmãos e seleciona os melhores alunos com base em seu desempenho, seguindo critérios definidos pela direção.

Os dois últimos casos descritos apontam o papel da burocracia tanto na escolha como na obtenção das vagas no processo de transferência interna. As alunas Luiza e Aline tiveram a influência de pessoas que trabalham nas escolas da rede para escolher a Escola I, mas somente Aline conseguiu a vaga. $\mathrm{O}$ fato de Luiza não ter sido aceita na escola desejada reforça a ideia de que a escolha com interferência de relações pessoais não necessariamente garante a obtenção da vaga. Ambos os casos, principalmente o de Aline, indicam que, em processos de 


\section{pro.posições}

transferência interna, a direção da escola de destino tem uma maior interferência no acesso à vaga, julgando os alunos com critérios não formais.

\section{O ponto de vista dos gestores sobre escolha e acesso às escolas}

As entrevistas realizadas com os diretores das escolas selecionadas indicam que, de início, as escolas de $2^{\circ}$ segmento apresentam o quantitativo de vagas que cada uma oferecerá. A partir do quantitativo de vagas disponibilizadas, as escolas elaboram os próprios critérios para definir quais serão os alunos que irão ocupá-las:

Direção Escola I: Então en falo lá [na reunião do polo] ... "eu tenho 100 vagas", "aí, eu preciso de tantos, de tantos, de tantos". "Então vai ser o quêe? Vinte pra cada um, se são cinco escolas?". "Ah, eu não preciso das 20, eu só preciso de 10", como acontece na Escola F. Ai a Escola A: "ah, então eu quero essas 10", mas ai tem a Escola B: "ah, mas eu preciso de mais 5", ai fica [sic] 5 pra cada um. Então ali, eu sou o último a me meter, porque senão ali eles mordem até a minha mão!

Entrevistadora: Então é uma articulação entre o $1^{\circ}$ segmento, né?

Direção Escola I: Entre quem quer mandar aluno pra cá. Vira e mexe, uma vez. ou outra, como foi o ano passado, ou ano retrasado, o Pedro, que é da Escola J, que é uma escola que fica lá dentro da favela ..., falou "tenho um aluno muito bom que quer ir pra tua escola". Falei: "ô, gente, o Pedrinho... como ele nunca manda aluno pra cá, já tenho uma vaga dele".

Esse relato evidencia que há uma organização do polo de escolas no remanejamento dos alunos. Além disso, mostra uma grande procura por vagas na Escola I, que gera disputa entre as escolas interessadas em enviar seus alunos para essa escola. As escolas remetentes possuem maior poder de decisão, embora, no caso relatado, o diretor da escola pretendida pelos pais tenha tentado influenciar na decisão sobre uma vaga, considerando sua visão sobre uma das escolas remetentes.

As entrevistas realizadas com os diretores também permitiram mapear os critérios utilizados por escolas de $1^{\circ}$ segmento para envio dos alunos para as escolas de $2^{\circ}$ segmento. $\mathrm{O}$ polo apresenta uma variação que inclui desde a escolha dos pais e o sorteio até a seleção de alunos de melhor desempenho por parte das escolas remetentes.

Direção Escola I: Ai cada escola tem seu critério. Por exemplo, a Escola $A$ aqui faz sorteio. A Escola B e a Escola $C$ fazem sorteio, mas só que da seguinte forma: participam primeiro os alunos que têm melhor conceito. Eles fazerm tipo uma seleção. Se o aluno é mais dedicado, tem um conceito melhor, ele tem direito de 


\section{pro.posições}

escolher primeiro. Então eles vão pegar aqueles MB. Vinte MB. Vamos imaginar que os $20 \mathrm{MB}$ querem vir pra cá. Mas eu só tenho 12 vagas. Então eles vão sortear entre os alunos MB, porque eles têm esse critério inclusive registrado em Ata. A Escola D que é aqui do lado nunca tem um critério assim muito claro. Às vezes é sorteio. Às vezes eles encaminham aqueles que eles acham que vai... têm mais chance de prosseguir mais em um estudo mais puxado, né, porque aqui a gente tem fama de ser uma escola que exige mais, que puxa mais. Então tem muito aluno, ou até responsável mesmo que nem quer que o aluno venha pra cá. Porque sabe que a chance de ele ficar reprovado é grande. Então nem quer.

O relato acima corrobora afirmações contidas nas narrativas das famílias sobre os procedimentos de escolha e acesso e demonstra que não há padrões claros, pois (1) cada escola de $1^{\circ}$ segmento adota um tipo de procedimento para selecionar os alunos que serão remanejados para a Escola I; (2) há ausência de rigor nos critérios de escolha dos alunos. A única escola que adota um mecanismo republicano, em que todos os alunos possuem as mesmas chances, é a Escola A, ao adotar a aleatoriedade. As demais utilizam critérios pautados na subjetividade, na arbitrariedade e em percepções individuais de professores e gestores escolares, além da nota dos alunos. Sobre os procedimentos adotados na Escola A, sua coordenadora pedagógica frisa:

Direção Escola A: a coisa tem que ser democrática, né? Quem vai pra lá tem que ser quem quer ir pra lá. Se tem uma procura maior do que a demanda, então que a coisa seja democrática. E eu acho, sinceramente, não consigo pensar em outra forma. Então mete a mão no saco e tira um número.

A escola A é a única a adotar procedimento aleatório para decidir quais alunos terão direito à vaga na Escola I. Ela apresenta a maior média de escolarização dos pais dos alunos e a maior nota na Prova Brasil Padronizada nesse polo. Portanto, seria lógico pensar que, nesse caso, a escolha aleatória não faria diferença, porque os alunos seriam semelhantes social e culturalmente. Porém, o diretor da escola I não concorda com essa visão. Ele é contra a utilização do sorteio como procedimento para escolher os alunos que serão remanejados e acredita que o sorteio ocorre por uma "birra" da diretora da escola A.

Direção Escola I: um dos motivos da Escola A fazer sorteio, que é até uma birra que eles têm, porque, tanto a direção anterior, quanto a direção agora, elas [sic] acham ou achavam que quem tinha que mandar aluno pra cá era a Escola A... Então eles já fazem sorteio. Eu já conversei: "Pô, Diretora A, faz assim, tal tal tal". Você já direciona, às vezes manda aluno que vai ficar reprovado, coisa e tal.

O que parece estar claro sobre o polo estudado é que os critérios articulados pelas escolas de $1^{\circ}$ segmento influenciam a composição do alunado nas escolas de $2^{\circ}$ segmento. Por 


\section{pro.posições}

exemplo, quando perguntada sobre a qualidade da Escola I, sua direção a atribui, entre outros fatores, ao perfil dos alunos que recebe das outras escolas.

Direção Escola I: Aqui a escola já criou uma fama, então muitas vezes a escola deixa escolher primeiro o aluno MB. Então a gente acaba recebendo mais alunos $M B$ do $1^{\circ}$ segmento, do que as escolas do entorno. Então é o efeito tostines: a gente rende mais, porque recebe alunos melhores e recebe aluno melhor... e por receber aluno melhor, rende mais. Acaba virando a escola que tem fama de boa e o aluno quer vir pra cá e o fato do bom aluno querer vir pra cá, acaba rendendo mais.

Podemos dizer que as escolas de $2^{\circ}$ segmento não participam do remanejamento dos alunos do $5^{\circ}$ para o $6^{\circ}$ ano. No entanto, o mesmo não acontece durante a transferência interna de alunos, que ocorre em qualquer período do ano letivo. Quando perguntado sobre os procedimentos durante a matrícula de alunos que pedem transferência, o entrevistado explica:

Direção Escola I: Normalmente a gente pergunta. E dependendo se for uma escola aqui do polo, se a gente tem certa intimidade com a direção, a gente pergunta .... "Pô, como é fulano de tal? Quer se matricular aqui". Aí eles me falam: "Ih, Diretor I, isso aí é uma peste", né, ou não: "Ah, é muito bom aluno". Então esse tipo de informação a gente pega também. Mas, quando vem de uma escola particular, normalmente a única informação que eu tenho é o histórico que ele traz ou é o boletim. Mas esse não é nem o nosso principal critério de seleção, não. O principal critério é proximidade.

Os dois casos descritos de transferência interna, das alunas Aline e Luiza, demonstram que a direção da Escola I tem interferência na concessão da vaga na escola desejada pelas famílias. Em ambos os casos não existem regras claras no processo de transferência. O caso de Aline, cuja tia era merendeira da Escola I e pediu para a direção que disponibilizasse a vaga, indica que a regra informal, no caso, a relação pessoal, influencia positivamente na obtenção da vaga na melhor escola do bairro.

A ausência de especificações e fiscalização sobre os procedimentos que devem ser adotados pelas escolas durante as transferências parece contribuir para práticas não aleatórias. $\mathrm{Na}$ Inglaterra, as escolas que se encontram em situação de maior demanda por vagas do que oferta cada vez mais utilizam critérios que priorizam crianças com algum tipo de desvantagem, seja social, médica ou educacional (West, Barham, \& Hind, 2011). Esses critérios impedem a recusa de alunos com determinado perfil. Há instâncias superiores às escolas que fiscalizam o cumprimento desses critérios, de modo a assegurar uma distribuição equânime de alunos entre as escolas. 


\section{pro.posições}

No Rio de Janeiro, por serem muito procuradas, as escolas mais prestigiadas estão em posição de skim cream $^{22}$ (West et al., 2004), ou seja, podem selecionar, de alguma forma, seus alunos. Ao menos na transferência, os atores da burocracia educacional agem como gatekeepers (Noreisch, 2007), ao desenvolver estratégias específicas para conceder ou não a vaga requerida, especialmente na ausência de mecanismos que impeçam as escolas de selecionar alunos.

As entrevistas evidenciam as limitações de escolas que não ocupam a posição de skim cream. A direção da Escola $G$ relatou um caso em que tentou recusar transferência de alunos, mas não teve sucesso. Ela explicou que, quando um responsável busca vaga ao longo do ano letivo, a direção faz um levantamento do histórico do estudante, a fim de averiguar a razão de estar procurando por vaga depois de as aulas já terem iniciado. Ela contou que uma mãe, na metade do ano, foi solicitar vaga para o filho que estudava em uma escola ao lado da Escola $G$ e, por ter sido repreendido por indisciplina, a diretora teria sugerido que ele trocasse de escola. A diretora da Escola $G$ recusou-se a receber o aluno, e a CRE entrou em contato com ela, pedindo para aceitá-lo ("quase pedindo 'por favor', pedindo com jeitinho...'). A diretora tentou recusar, ao questionar "por que ele tem que vir pra cá?", mas, no fim, o aluno ingressou na Escola G.

Essas evidências sugerem capacidades diferenciadas de seleção das escolas, de acordo com sua reputação. É possível levantar a hipótese de que as escolas mais procuradas conseguem administrar a liberação ou não da vaga escolar requisitada, enquanto as escolas menos procuradas encontram entraves para recusar alunos. Essa diferença seria ocasionada pelo fato de as escolas mais procuradas terem maior demanda do que vagas a oferecer, enquanto nas menos procuradas aconteceria o contrário.

\section{Considerações finais}

As fragilidades que as regras de matrícula na rede municipal do Rio de Janeiro apresentam permitem diversas interpretações em relação ao remanejamento e à transferência. Os atores envolvidos na distribuição dos alunos interpretam as regras de matrícula de

\footnotetext{
${ }^{22}$ Uma possível tradução para o conceito de skim cream utilizado por West et al. (2004) seria "separar a nata".
} 
diferentes formas. A partir disso, desenvolvem critérios e apresentam justificativas para aceitar ou rejeitar alunos.

Os resultados mostram a existência de segregação escolar circunscrita aos agrupamentos geográficos de escolas e revelam padrões claros de transferência de alunos entre escolas com determinado perfil. Evidências mostram que processos que influenciam a composição do alunado não se restringem à autosseleção ou à escolha das famílias por escolas. As famílias adotam diferentes estratégias de escolha e de acesso às escolas selecionadas. Ao mesmo tempo, os atores que compõem a burocracia educacional exercem papel decisivo na alocação dos alunos nas escolas, ao estabelecer critérios não aleatórios para concessão de vagas. As famílias, por sua vez, revelam que as direções escolares exercem domínio pessoal e arbitrário na aceitação dos alunos nas escolas, limitando as possibilidades de escolha por parte das famílias.

Ao final, podemos indicar que tanto o remanejamento quanto as transferências internas não são regidos exclusivamente por critérios republicanos. Essa situação faz com que as desigualdades presentes entre as escolas, assim como as segmentações inerentes aos polos de matrículas, sejam mantidas a cada ano. Parece haver certo nível de consenso entre os segmentos da burocracia educacional - e até mesmo entre as famílias - sobre a presença de desigualdades e sobre a necessidade de manutenção de escolas diferentes para alunos diferentes. Talvez seja possível dizer que o enfrentamento desse conjunto de percepções e ações a elas relacionadas seja o principal desafio para a construção de sistemas educacionais universais e equânimes no Brasil. 


\section{pro.p̣osıções}

\section{Referências Bibliográficas}

Alegre, M. A., \& Bentino, R. (2012). The best school for my child? Positions, dispositions and inequalities in school choice in the city of Barcelona. British Journal of Sociology of Education, 33(6), 849-871.

Ball, S. J., \& Vincent, C. (1998). 'I heard it on the grapevine': 'hot' knowledge and school choice. British Journal of Sociology of Education, 19(3), 377-400.

Bell, C. A. (2005). All choices created equal? How good parents select "failing" schools (Working Paper). New York: Columbia University, National Center for the Study of Privatization in Education, Teachers College.

Bruel, A. L. (2014). Distribuição de oportunidades educacionais: o programa de escolha da escola pela familia na rede municipal de ensino do Rio de Janeiro (187 pp.). Tese de Doutorado em Educação, Universidade Federal do Rio de Janeiro, Rio de Janeiro.

Bruel, A. L., \& Bartholo, T. (2012). Desigualdade de oportunidades educacionais na rede pública municipal do Rio de Janeiro: transição entre os segmentos do ensino fundamental. Revista Brasileira de Educação, 17(50), 303-327.

Carvalho, J. T. de. (2014). Segregação escolar e a burocracia educacional: uma análise da composição do alunado nas escolas municipais do Rio de Janeiro (153 pp.). Dissertação de Mestrado em Educação, Universidade Federal do Rio de Janeiro, Rio de Janeiro.

Costa, M. (2008). Prestígio e hierarquia escolar: estudo de caso sobre diferenças entre escolas em uma rede municipal. Revista Brasileira de Educação, 13(39), 455-469.

Costa, M., Alves, M. T. G., Moreira, A. M., \& Sá, T. C. D. (2013). Oportunidades e escolhas: famílias e escolas em um sistema escolar desigual. In M. A. Nogueira, N. Zago, \& G. Romanelli. (Eds.), Familia e escola: novas perspectivas de análise (pp. 131-164). Petrópolis, RJ: Vozes.

Costa, M., \& Koslinski, M. C. (2011, janeiro/abril). Quase-mercado oculto: a disputa por escolas comuns no Rio de Janeiro. Cadernos de Pesquisa, 41, 246-266. 


\section{pro.posıções}

Costa, M., Prado, A. Pires do, \& Rosistolato, R. (2012, junho). "Talvez se eu tivesse algum conhecimento...": caminhos possíveis em um sistema educacional público e estratificado. Interseções, 14(1), 165-193.

Elacqua, G. (2012). The impact of school choice and public policy on segregation: Evidence from Chile. International Journal of Educational Development, 32(3), 444-453.

Glenn, C. (2009, março). School segregation and virtuous markets. In: Penser Les Marches Scolaires. Genebra/Suíça: Groupe Genevois d'Analyse des Politiques Éducatives GGAPE (Université de Genève, Faculté de psychologie et des sciences de l'éducation). Réseau d'Analyse Pluridisciplinaire des Politiques - RAPPE.

Gorard, S., Taylor, C., \& Fitz, J. (2003). Schools, markets and choice policies. New York: Routledge Falmer.

Holme, J. J. (2002). Buying homes, buying schools: school choice and the social construction of school quality. Harvard Educational Review, 72(2), 177-205.

Koslinski, M. C., \& Carvalho, J. T. de. (2015). Escolha, seleção e segregação nas escolas municipais do Rio de Janeiro. Cadernos de Pesquisa, 45, 916-942.

Koslinski, M. C., Costa, M., Bruel, A. L., \& Bartholo, T. (2013, novembro - 2014, fevereiro). Caminho marcado: transição entre escolas públicas municipais na cidade do Rio de Janeiro. Educação em foco, 18(3), 83-115.

Nogueira, M. A. (2005). A relação família-escola na contemporaneidade: fenômeno social/interrogações sociológicas. Análise Social, 40(176), 563-578.

Noreish, K. (2007). Choice as rule, exception and coincidence: parents' understandings of catchment areas in Berlin. Urban Studies, 44(7), 1307-1328.

Resende, T. F., Nogueira, C., Marques, M., \& Nogueira, M. A. (2011). Escolha do estabelecimento de ensino e perfis familiares: uma faceta a mais das desigualdades escolares. Educação \& Sociedade, 32(117), 953-970.

Rosistolato, R. (2015). Choice and access to the best schools of Rio de Janeiro: a rite of passage. Vibrant, 12, 380-416.

Rosistolato, R., \& Pires do Prado, A. (2012). Escolhas familiares e estratégias de acesso às escolas do sistema municipal de educação do Rio de Janeiro: navegação social em um 


\section{pro.posições}

espaço de disputa. In Anais, 36 Encontro Anual da Associação Nacional de Pós-Graduação e Pesquisa em Ciências Sociais - ANPOCS (pp. 1-30). Águas de Lindóia: Associação Nacional de Pós-Graduação e Pesquisa em Ciências Sociais.

Rosistolato, R., \& Pires do Prado, A. (2013). Trajetórias escolares em um sistema educacional público e estratificado. In Anais, 16 Congresso Brasileiro de Sociologia (vol. 1, pp. 1-20). Salvador.

Rosistolato, R., Pires do Prado, A., Moreira, A. M., \& Fernandes, I. (2015). Patrimonialismo e seleção de alunos em escolas públicas cariocas. In Anais, 17 Congresso da Sociedade Brasileira de Sociologia. Porto Alegre-RS.

West, A., Barham, E., \& Hind, A. (2011). Secondary School Admissions in England 2001 to 2008 changing legislation: policy and practice. Oxford Review of Education, 37(1), 1-20.

West, A., Hind, A., \& Pennell, H. (2004). School admissions and 'selection' in comprehensive schools: policy and practice. Oxford Review of Education, 30(3), 347-369.

Yair, G. (1996). School organization and market ecology: A realist sociological look at the infrastructure of school choice. British Journal of Sociology of Education, 7(4), 453-471.

Submetido à avaliação em 14 de setembro de 2015; aceito para publicação em 18 de março de 2016. 
